\section{CASES OF TRACHEOTOMY IN DIPHTHERITIC CROUP.}

BY AUG. M. TUPPER, M.D., OF ROCKPORT, MASS.

Trousseau is credited with saying that "tracheotomy badly performed, but well treated afterwards, will end favorably in a third of the cases, whereas tracheotomy excellently executed but badly treated afterwards will almost invariably be followed by a fatal termination."

Meigs and Pepper say, "whenever it is in any way possible, the constant presence, day and night, of a physician or student of medicine should be secured for four or five days after the operation ... the child should never be without the presence of some one competent and ready to render the prompt assistance which is frequently necessary to avert instant death."

J. Lewis Smith, in his "Diseases of Children," remarks that " no surgical operation more imperatively demands intelligent and attentive after-nursing than tracheotomy." Now, while I entirely agree with the above quotations, and can well understand the relief and comfort it must be to the physician to know that during his absence his patient is in the hands of a medical friend or skilled nurse, I believe that many times we can attain success under most unfavorable conditions, and when we have to depend entirely upon ourselves for the care, as well as the treatment, with what can be taught the parents and friends at the time. By making frequent visits, and spending the nights, if possible, in the same house with the patient, we shall often be able to succeed, without the trained assistance which is so desirable when it is possible to procure it.

The following cases, by the recovery of two out of the five, go towards proving this, I think, particularly the last one, and it is in the hope that they may prove interesting and encouraging, especially to those who, like myself, are living away from the medical centres, and where the professional nurse is not at hand, that $I$ venture to report them. All were diphtheritic, as proved by the presence of false membrane in the fauces, and the prevalence of diphtheria in the vicinity, and are reported from notes written at the time, and partly from memory.

CASE I. A boy, seven and a half years old, who recovered, has already been reported in the JournaL, October 1Ith, 1877.

Case II. Female, aged six years and nine months. Went to bed September 21st, 1879, apparently well. The next morning (September 22d) did not want to get up, and complained of headache and sore throat. When I first saw her, the tonsils were very much swollen, and large patches of diphtheritic membrane could be seen upon them. There was a copious discharge from the nostrils, and the breathing was labored.

September 23d. 'This morning she is much worse, the swelling in the throat has increased, the tonsils nearly meeting, and her breathing is much obstructed. The nasal discharge has also increased. In short, she presented the appearance of one of those severe cases of diphtheria with which we are all familiar, with the addition of the croupy symptoms.

3 P. M. Growing worse rapidly, and the respiration being still more embarrassed, I decided that tracheotomy offered the only chance, and that a very slight one, on account of the great amount of systemic infection. However, the operation was done at 4 P. M. The trachea was small and deeply situated. At first we thought the tube was too large, and tried wire bent in the shape of hooks, but could not make it answer very well, and finally got our only canula in place. She was much relieved, and at 10.30 P. M. was sleeping pretty comfortably, but her pulse was very small and too rapid to be counted. The nose continued to discharge freely. We gave her injections of brandy, milk, and eggs as frequently as the rectum appeared likely to retain them. Did not try to make her swallow, the throat being so much swollen as to make it very difficult for her to take nourishment by the mouth. The operation was of great relief to this patient, and she continued comfortable until 2 A. M. of the 24 th, when she died very quietly and easily.

I have sometimes felt that this child had better not have been operated upon, but when we read what such a man as Jacobi says about these cases, ${ }^{1}$ namely: " no alleged contraindication to tracheotomy, whether the tender age of the patient, or a complication with either an inflammatory or an infectious disease, must be considered valid. The one strict indication for the performance of tracheotomy is when the diagnosis of pseudo-membranous laryngitis is undoubted. The increasing dyspnoea, cyanosis, and approaching asphyxia with the certainty that a well-directed aud efficient medicinal treatment has been, and in all probability, will be useless ; even under these circumstances, there is no mathematical certainty. The matured experience of a well-informed and thoughtful physician will commit but few errors. If there be the slightest doubt, the operation ought to be preferred to suffocation." When we read such conclusions, we must feel that we have done for the best, given our patient every possible chance, and, at least, a merciful death.

CASE III. Boy, aged six years and two months. Taken with diphtheria November 26th, 1879. Was hoarse from the first, but had no difficulty in breathing until Wednesday, December 3d, when he began to breathe harshly, and to cough occasionally.

Thursday, 4th. The difficulty in respiration had increased, and he had several attacks of spasm of the glottis.

Friday, 5th. He seemed better in the morning, and continued so until 4 P. M., when he grew worse, and began to suffer from dyspnoea continuously. The difficulty in breathing increased very much until 10 P. M., when tracheotomy was performed. There were several large veins in the line of incision, and the hæmorrhage was considerable, and when the trachea was opened, blood escaped into the windpipe and nearly suffocated him, but by vigorous effort, and performing artificial respiration through a catheter, he was resuscitated. He soon fell asleep, and passed a very comfortable night.

December 6th, 2.30 P. м. Has coughed a good deal to-day, but not raised much, still he seems in pretty fair condition. His pulse has been below 100 up to last night, when it reached 130 to 140 ; since he recovered from the operation it has been about 120 . Respiration not counted, but certainly as high as 60 ; it is now 48 , and he is sleeping quietly. I have not been able to keep the inner canula in place; he coughs very much, and does not breathe as well as when he has the outer tube only. Not much false membrane has been seen, and before the operation it had de-

1 Pepper's “ System of Medicine," Vol. III. 
creased; only a patch half as large as the thumbnail remained on the back of the right side of the throat.

December 7th, 9 A. M. Was pretty sick yesterday afternoon and last night; breathing a good deal obstructed, partly from mucus and partly from false membrane, at least I think so, from the sound of the cough and character of the breathing. There is a peculiar clicking sound at the end of inspiration, as if a piece of membrane partly detached was acting as a valve. I have heard this sound since, and regard it as an ominous sign, as significant of an extension of the disease below the opening. I am obliged to use the outer canula only most of the time, as he does not breathe as well with the inner tube in place. Took the tube out completely last night, at seven o'clock, and again this morning, at half-past six; neither time did it relieve him much, showing the obstruction to be in the trachea, and not in the canula. Pulse and respiration remain about the same, 120 to 130 , and 45 to 50 , respectively. Just now I removed the tube again, and think he seems easier for it. Intend leaving it. out for a while, as there seems to be phlegm and membrane not completely detached, and I fear it may be too large to get out through the canula.

December 8 th. 'The distress in breathing continued to grow worse, the pulse rising in frequency and exhaustion coming on. He finally died of asphyxia at nine last night, after suffering very much for six hours previous.

He never coughed up any false membrane and very little mucous, although at times it seemed very loose. This case was at first a very promising one, more like a case of ordinary croup, as very little membrane was seen upon the fauces and the constitutional symptoms were very slight. I could not even get him put to bed until he began to have distress in his breathing. His hoarseness made me feel uneasy of course, and I watched him very closely all the while. It illustrates how difficult it is to tell how far the diphtheritic membrane may go before it has reached its limit, and also how late in the case we may have the larynx and trachea attacked, even after the membrane has begun to disappear from the throat.

Case IV. Boy aged nine years and two months. Taken with diphtheria December 31st, 1880. First seen January 1st, 1881. Has had a cold for two or three days. Tonsils swollen and patched with false membrane.

January 2d. Mother says he had a croupy attack last night and that his cough is croupy.

January 3d. Croupy symptoms have increased and his breathing has become so much obstructed that tracheotomy was performed at ten this morning. The operation was a very easy one, he was much relieved, and now, 10 r.M., the breathing is very easy and noiseless and he is sleeping like an infant.

January 4th. Rested well last night, but coughed a good deal, and I have had to take the inner tube out, consequently have a good deal of trouble in keeping the canula clear. At noon he had a severe attack of dyspnoa and his mother cut the tapes and removed the tube, the removal being followed by violent cough and expulsion of a large piece of false membrane, a cast of the trachea, an inch long. On my arrival, some two hours after, I reintroduced the tube, and although at first he breathed hard and coughed a good deal, he is now, 3.30, P.M., quite easy.
January 5th. Had a very comfortable night last night, but this morning the tube had to be left out. P.M. Breathing becoming more and more obstructed, the disease has evidently gone below the opening. He suffers a good deal and requires constant use of the atomizer. Has frequent paroxysms of dyspnœea, and died in one at 6 P.M. 'The pulse did not go over 130 , and he took his food and medicine well up to the last moment.

I might mention that so afraid was every one of the disease about that time that I had a difficulty in getting anybody to come in and assist Dr. Manning and myself during the operation, and the young man I finally procured was not allowed to enter his sister's house, where he boarded, for several days, for fear he should bring the disease to some of the family.

Case V. Female, aged two years and eight months. First called November 22d, 1885. Her mother says she has had a cold for two or three days and been hoarse. I found her breathing harshly, with a croupy cough and all the symptoms of commencing laryngeal obstruction. Did not look in her throat, it being after lamplight I knew I could not see satisfactorily. Commenced the bichloride treatment, ordered steam to be generated in the room, and gave an emetic.

November 23d. Visited her early and found the symptom of obstruction very much increased. Examination of the fauces showed both tonsils coated with false membrane. Advised tracheotomy and performed it as soon as I could get help and instruments. Before the completion of the operation, on account of the failure of the pulse, although the respiration continued good, the trachea had to be opened before it was fairly exposed. Brandy was administered hypodermically and she soon rallied.

This case did as well as one could wish, there never was any trouble from obstruction and the breathing was easy and most of the time noiseless, with the exception of one night, but by using the atomizer faithfully and exciting cough by passing a feather down the tube, relief was obtained and there was no further difficulty on that account. All attempts at removing the tube permanently failed up to December $27 \mathrm{th}$, al most five weeks, when she was able to breathe through the larynx comfortably for a short time. Until then she could do very well about long enough to remove and clean the canula and sew on new tapes, when she would begin to be distressed and the tube would have to be replaced, and quickly, too, sometimes. After December $27 \mathrm{th}$, we would remove the inner tube and cork up the outer, which had a slot in it, for several hours each day. Still the canula could not be removed permanently. She could breathe through the larynx with the tube in place and corked, but if it were taken out she would have what seemed to us spasm of the glottis. She coughed a good deal, and often the expectoration would be bloody, occasionally pure blood. The bloody expectoration continued until I changed the tube for a smaller one.

On January 5̃th, 1886, I took out the canula, and staving some little time found she was breathing well, and as each time it was removed the mother was instructed how to replace it and made to do it herself, so she could respond to an emergency, I left, directing her to reintroduce it at 4 P.Mr., and before that if she began to be distressed. At the appointed time the mother attempted to replace the tube, and failing sent for me. On my arrival, two hours later, I found the 
granulations which existed around the outer edge of the wound had closed in and filled up the opening. I tried to get the canula in and failed likewise, but finding the child breathing well, without any distress, did not persevere in my attempts, but decided to leave matters as they were. Suffice it to say the child slept well all night and never had any trouble afterwards, and in about two weeks the opening was entirely closed.

It is this case I would speak particularly of, for there are several unusual and interesting features about it, one of which is the size of the tube. It is advisable to use as large a tube as can be introduced easily into the trachea. For the first few weeks I used one which was slightly larger than that nsed in my first case. It was inserted very easily, but I think was rather large and probably accounted for the bloody expectoration. It was afterwards changed for the same one worn in Case I, and it will be remembered that he was seven and a half years old, while this patient was only two years and eight months. Dr. R. W. Parker, in the Lancet, February 7th, 1985, says : " slight differences in the length of the tube, in depth from the front opening to the angles and in calibre, I believe, often turns the balance one way or the other. A tracheotomy tube, like a boot, must fit comfortably, or it cannot be worn without injury." Yet here are two children, with almost five years differences in their ages, wearing the very same tube and both recovering.

Another feature is the rapid filling up by the granulations of the external orifice of the wound, thereby preventing the reintroduction of the tube when left out a few hours, which might have proved a very serious matter and illustrates the importance of keeping these granulations down by the use of caustics or scissors. The most interesting and unusual complication is the prolonged retention of the canula, fortyfour days. In any case it is advisable to remove the tube at the earliest moment which is practicable, as the prolonged retention may be a source of danger in several forms, such as ulceration, hæmorrhage, and a formation of granulations in the trachea.

Meigs and Pepper, after quoting Trousseau as saying the removal may be delayed fifteen to twentyfour or forty-four days or even longer, give the causes as summed up by Mr. Mash, as:

"1st. Obstruction of the larynx by false membranes which have been known to linger in its cavity for at least fourteen days after this operation.

" $2 d$. A chronic inflammation and thickening of the mucous membranes of the larynx which may remain after the acute disease has passed off.

" $3 \mathrm{~d}$. A narrowing or complete obliteration of the passage of the larynx by a growth of granulations above and around the canula.

"4th. An impairment or complete loss of those functions of the muscles of the larynx which regulate the admission of air through the rima glottidis.

" 5 th. Adhesion of the opposed surfaces of the vocal cords."

Another cause which may delay the removal is nervousness. The child accustomed to breathe through the tube, on finding it removed and air passing through the natural channel, becomes alarmed and spasm of the glottis ensues, and this of course increases the terror, each reacting upon the other. Parker relates a case in which the removal was delayed in part on that account. To which of these causes the difficulty was due in the present case, it is hard to determine positively, but I am inclined to attribute it to two, namely, the presence of granulations in the trachea and also to spasm, the latter being induced part of the time by the existence of the granulations. The fact of there being granulations at the external orifice would go to prove the probability of their presence also at the inner. The pressure of the tube keeps them back, but a short time after its removal they swell up and if they are sufficient in quantity may occlude the trachea, at least that is the explanation Parker gives. The bloody expectoration while wearing the larger tubes was also indicative of irritation and ulceration perhaps. It is rather provoking to read in the text-books of the causes of the delay in the removal of the canula, but to find nothing on the treatment of such complications. Parker recommends the local application of nitrate of silver fused on a silver probe, suitably bent, and applied to those parts on which the granulations are supposed to exist, or a solution of the nitrate, thirty grains to the ounce, a few drops allowed to trickle into the trachea, one of which methods I should certainly adopt in another case. His articles in the Lancet, January 24th, 31 st, and February 7 th, 1885 , are valuable ones and well worth reading. Thus far I have said nothing about the treatment of these cases, but medicinally it consisted of a continuation of a Tr. Chloride of Iron and Chlorate of Potash mixture given frequently, and small doses of a solution of carbolic acid also administered frequently, when they took anything, for in some of them it was impossible to give any medicine except a little carbonate of ammonia; of course they were fed as nutritiously as possible. Troussean states that as soon as the trachea is opened the diphtheritic process comes to a standstill in the pharynx. The great point is to keep the canula clear, and in order to accomplish this the inner tube must be frequently removed and cleaned. My plan has been whenever the breathing became noisy or obstructed, to use the steam atomizer, placing the mouthpiece close to the opening, protecting the patient from being wet by the spray by means of towels, etc., when, if not improved by the inhalation, remove the inner tube and clean it, and if neither of these measures succeed in rendering the respiration easy, steam through the outer canula and pass a feather down into the trachea so as to excite cough and expel the phlegm or membrane which is very likely the cause of the difficulty. The steam atomizer is invaluable in these cases, in my opinion, but I think that steam from water alone or a weak solution of carbolic acid is as useful as any of the so-called solvents. I have seen the little patients motion and point for the atomizer, because it relieved them, and one poor little fellow in his agony would grasp the mouthpiece and hold it to the opening himself, thereby giving mute but eloquent testimony of its utility.

It has been noticed that in some of these cases we were obliged to leave out the inner tube, because the breathing was easier with the single outer canula only. Why this was I do not know, unless the instrument was too small. Profiting by experience, I should hereafter use larger tubes at the same age. Possibly the result might have been more favorable had I been better provided. The rooms were kept warm $\left(75^{\circ}\right.$ to $80^{\circ}$ ), and the atmosphere charged with steam, but in the last case the amount was small, owing to circumstances. 
To strengthen my assertion that tracheotomy can be successful in diphtheria under most unfavorable conditions, I would like to relate some of the circumstances of the last case. The father was a teamster and the home none too comfortable, while the hygienic arrangements left much to be desired. As soon as the disease was declared diphtheria all the neighbors at once departed, leaving the mother and the doctor to do all the nursing and take care of the family besides, for the father having had a brother return from the West after a long absence, celebrated his return and the " miracle" which was being done on his child, in the too common manner, with the usual result, and was of no help for the first two or three days. The first night about 2 o'clock I came down stairs to see how matters were progressing, to find the mother and the patient sound asleep on the bed, and this brother referred to, who had promised to keep awake and watch, lying on the floor also asleep. The mother on the fourth day was attacked by the disease, but the attack proving light, was able to keep on her feet and attend to the child.

In regard to the operation itself, it is not generally a difficult one, but it is very encouraging to those of us who are not in the way of seeing or doing much surgery to find an author like Trousseau saying "provided the canula be introduced into the trachea it really matters little how that has been accomplished, whether the operation has been performed with more or less dexterity, or with more or less rapidity, the result is the same provided there has not been hæmorrhage," and again, Parker, who writes "It is hardly probable that the various structures found in front of the trachea will be individually recognized during the performance of a tracheotomy."

If one will look through the medical journals for the last ten years he will see how much more frequently the operation is done than in the past, and how many more successful results been obtained. I well remember how an old, experienced and able physician discouraged the attempt in my first case, because it was diphtheritic, but I venture to predict that the time is coming, if not here already, when the physician will be just as much expected to open the trachea of a child dying from eroup, diphtheritic or not, as he is expected to set a fractured limb or tie a wounded artery.

Since writing the foregoing paper, I have been called to a neighboring village in consultation, to see a child with croup, on whom I operated. The nursing was done entirely by the relatives, the case doing perfectly well and the canula removed permanently on the twelfth day. The operation was done in the kitchen, the patient remaining there until well, it being the only room where it was possible to get the necessary amount of steam generated.

\section{THE DELAYED REMOVAL OF TRACHEOTOMY TUBES, WITH CASES. \\ BY ROBERT W. LOVETT, M.D.}

Firmerly House Surgeon at the Boston City Hospital.

AFter the performance of tracheotomy in children there is seldom any difficulty in dispensing with the use of the trachea tube after a few days. At the Boston City Hospital in about three hundred tracheotomies there have only been four cases which presented this difficulty. Ordinarily at the Hospital the tube is removed on the fifth, sixth, or seventh day by cutting the tape and quietly taking it out. No preliminary testing of the passage of air through the larynx by stopping the tube is attempted, and in the overwhelming majority of cases laryngeal breathing is fully established by the time that the tracheal opening is cicatrized. The following four cases are the only ones in which tubes were worn for any considerable time.

I. J. E. C., a fat little boy fifteen months old, a nursing baby, was admitted with his mother May 29, 1885. He had been distressed for breath for two days and at the time of admission he was suffering from very severe dyspnœa with retraction of the soft parts of the chest at each inspiration. There was grayish membrane upon both tonsils, and the glands of the neck were much enlarged. 'Tracheotomy was at once done by the House Surgeon, and afforded relief. His progress was very favorable, he nursed quite well, drank a few ounces of milk daily, and was but little prostrated. On the sixth day (June 4) the tube was taken out at 11 A.M. and the child breathed quietly without it. At 3 P.M., of the same day, he had such a violent attack of dyspnoea that he would have died had not the nurse at once replaced his tube. He rallied quickly from the extreme prostration caused by this attack and breathed without further trouble until three days later (June 7) when the tube was removed again, but dyspnoea came on at once and it had to be replaced. For two weeks from this time his condition continued the same. His tube was taken out daily, but he was unable to breathe without it and it was always necessary to put it back at once. 'The wound had closed around the tube and no exuberant granulations were to be seen. It seemed as if the trachea collapsed when the tube was taken out, and so shut off the entrance of air to the lungs. Air certainly passed through the larynx when the tube was stopped, and he began to talk aloud June 22d, in a husky but fairly loud voice. The wound was painted daily with a saturated solution of alum and a smaller but still fenestrated tube was put in. He went out of doors daily and improved in his general condition until July 20 , when he was discharged wearing his tube. He reported at the Out-Patient Department from time to time to Dr. Hooper and was under his care until November 15,1885 , when be was readmitted to the hospital for another attempt to remove the tube. It came out with difficulty and a small mass of granulation tissue which had grown through the fenestrum into the tube, was pulled away with it. The boy struggled and strangled a little, but in five minutes he was breathing quietly and the tube was left out, although it had been intended to insert a smaller and a nonfenestrated tube. He had a very croupy cough for two nights and breathed rather noisily when asleep, but without distress. November 21,1886 , he left the Hospital; the wound was closed, his voice clear and natural, and his breathing perfectly normal. He has continued in this condition.

II. Albert W., four years old, was admitted July 5, 1885 , suffering from severe dyspncea. He had had whooping-cough three months previously, and was now suffering from measles, the eruption of which was just disappearing. He had been distressed for breath for three days, and at the time of admission he was struggling with every inspiration and somewhat cya- 